\title{
IT to Enhance Tourism Industry Integrating Innovation: Paths Analysis and Empirical Test ${ }^{1}$
}

\author{
Zhu Haiyan ${ }^{1,2}$ \\ ${ }^{1}$ Tourism and Environment College, Shaanxi Normal University, Xi'an, Shaanxi, China, 710127 \\ ${ }^{2}$ Yulin University, Yulin, Shaanxi, China, 719000
}

Key words: IT, tourism industry, integration, innovation

\begin{abstract}
Information technology has gradually penetrated into tourism industry, and integrated with it rapidly. Previous studies mainly aimed at information technology as a driving force for the integration of the tourism industry, this paper from the perspective of industrial integration, buildsthe path model in which IT promotes the tourism industry to integrate and innovate. Meanwhile, it makes an empirical analysis on that IT drives tourism industry to converge with it based on the relationship of industry concentration degree and convergence degree. The results show that the tourism industry concentration degree and the integration degree between this two industry have no significant correlation, while information industry concentration degree and the integration degree between this two industry show a significant correlation, the correlation coefficient is 0.329.It is suggested that tourism industry has no significant leading role in promoting this two industry's convergence, while information industrymanifests a strong role in promoting their convergence.
\end{abstract}

\section{Introduction}

Information technology is the symbol of the third science and technology revolution. The tourism industry has got a rapid development in the transformation of the scientific and technological revolution with the information technology at the core. Sabre developed a global distribution system (GDS) capable of providing transportation, accommodation, entertainment, payment and other travel related services in 2000. In 1990s, with the popularity of personal computers and the Internet, tourism e-commerce began to develop rapidly. The application of information technology in tourism in China is lagging behind about 20 years in the world. However, with the guidance of relevant policies, China's tourism informatization has been rapid developed in the recent years. Information technology has gradually penetrated into the tourism industry, between the tourism industry and the rapid development of fusion, gave birth to the tourism new products "and" new format, change the tourism industry marketing mode, and improve the service quality of tourism. Information technology brings to the tourism industry of great change and innovation has been the consensus, however, information technology how to promote integration of tourism industry innovation and the promotion of the integration of tourism industry and promote the intensity of the size of the problem in theory and practice has not been explained and validated. Therefore, based on the existing research, this paper constructs thepaths of promoting tourism industry integration and innovation by the information technology path. Based on the paths analysis, this paper makes an 
empirical study onthe promotion of tourism industry by information industry in 30 provinces and cities in China.

\section{A Literature Review on the Integration of IT Industry and Tourism Industry}

The research of industry integration in the academic field originates from the industrial cross phenomenon caused by the digital technology. In the recent years, the research on the integration of tourism industry has gradually increased, and the main research results about the integration of information industry and tourism industry focus on the following aspects:

$\mathrm{Xu}$ Hong, Fan Qing (2008) believed that technological innovation is the external power of tourism industry convergence. Liu Xueting (2011) that the intrinsic reason is not technology integration the integration of the tourism industry, but it is an important catalyst to provide aid and technical support ofinnovation for tourist activities. Yang Yanfeng (2012) believes that tourism is an information intensive and information-based industry, coupled with the natural and information technology, the information technology represented by the Internet has become the main driving factors and new forms of tourism industry convergence. Liu Yuqing (2009) on the permeability of high tech to the tourism industry of tourism industry convergence changed the tourism business model. Ma Xuefeng (2010) put forward the technology integration refers to the tourism industry to actively introduce other related technology, and even some industry technology advantage into the tourism industry, the formation of new tourism industry. Study on the integration of information technology innovation in the tourism industry. Yang Yanfeng (2012) believed that the integration of the tourism industry and the new tourism industry is essentially a kind of innovation, the integration of information technology and the tourism industry is also the innovation of industry. Ma Xuefeng (2010) put forward the tourism innovation must take some technical means as the basis, therefore, the tourism industry to actively introduce the relevant technology of other industries should be integrated into the tourism industry, the formation of new tourism industry. Gao Lingjiang, Xia Changjie (2012) believed that the technology innovation bringsindustry system innovation, management innovation and market innovation as the tourism industry, and ultimately change the mode of development of the tourism industry. About the force of the integration of information technology in the tourism industry are holding a positive view in the current study, only in the information technology is the integration of the tourism industry the main driving factor is the external force on the catalyst or controversial. About how to promote the information technology innovation path analysis of tourism industry convergence is not given the relevant model or a clear definition, research method is mainly qualitative analysis, quantitative research is extremely rare. Integration of innovative information technology in the tourism industry, the study proposes new formats, new industry or management system and management, but the lack of analysis of tourism industry chain in different parts of specific innovations. Therefore, based on the existing research, this paper constructs the path model of information technology promoting the integration of the tourism industry. It clearly defines the innovation results in different parts of the tourism industry chain.

\section{Model Construction of the Paths of Integrating Innovation of IT Industry and Tourism Industry}

When the information industry and the tourism industryintegrate, information technology has the basic nature to promote the tourism industry as the information technology is pervasive, driving and multiplying. The nature of penetration of information technology makes the information industry 
convergence penetration of traditional industries become possible, driven by the information industry to become the leading industry integration industry, doubling the characteristics of the information industry to low cost expansion, rapid development of new business and market, accelerate industry integration. The fusion of information technology to promote the tourism industry, the tourism industry needs to have the common and basic application of technology on the basis of innovation.The technology can be used in a certain part of the tourism industry chain innovation, so as to achieve the link. In the development of tourism resources, intelligent terminal technology that other applications in digital navigation, electronic map, location, virtual tourism resources application and the Internet of things technology in the field of electronic ticket, travel card, scenic resource management in the development of tourism resources is more creative and attractive, more efficient and convenient management of scenic spots. Production of tourism products, appeared based on information technology, electronic guide system, remote conference system, intelligent hotel management system etc.. At the same time, part of the information technology into the tourism industry with its technical advantages, the formation of a new tourism. The popularity of the Internet technology and personal computer spawned a new form of tourism e-commerce tourism products sales become more convenient and quick. At the same time, it has changed the structure of tourism enterprises, making the original large department without redundancy.

The integration of tourism industry and information technology industry is still based on the analysis of qualitative methods. It is unable to confirm the integration phenomenon of the tourism industry and information technology industry. It also cannot give a clear integration degree of information technology industry and tourism industry. Therefore, this paper will make an empirical test of the agglomeration degree and integration degree of it industry and tourism industry.

\section{Empirical Test of the Integrating of IT Industry and Tourism Industry}

Research Method and Data Resources. In order to ensure the consistency of the data statistics, the data of agglomeration degree and integration degree of this paper are derived from the input output table in 2007. Considering the availability of data, the location entropy index is selected to measure the degree of agglomeration of tourism industry and information industry. The formulation is:

$$
L Q=\frac{E_{i j}}{E_{i}} / \frac{E_{k j}}{E_{k}}
$$

The economic meaning is the value of the industry in a given region and the share of the industry's share in the whole economy. Here i refers to the $E_{\mathrm{ij}}$ region industry $\mathrm{j}$ employment (output value), $E_{i}$ refers to total employment (total output value) of I region, $E_{k j}$ refers to the state or regional $\mathrm{k}$ industry $\mathrm{j}$ total employment (total output value), $\mathrm{E}_{\mathrm{k}}$ refers to the total employment of state or regional $\mathrm{k}$ (total output value). When the LQ is greater than 1 , it means the agglomeration degree is higher than the average agglomeration. In this paper, we need to measure the degree of integration of the information industry and tourism industry in 30 provinces and cities in China. Based on the availability of data, we select input and output calculation method to calculate the degree of integration of the information industry and tourism industry. The formulation is:

$$
T=\frac{U}{I} * 100 \%
$$

$\mathrm{T}$ refers to the integration of the information industry and tourism industry, $\mathrm{U}$ said the tourism industry in the production process of investment in the information industry, I said tourism industry output value. Because u represents the fusion of information industry and tourism industry output, 
so this calculation method, to a certain extent underestimated the degree of integration of the information industry and the manufacturing industry, but considering the overall trend, it doesn't make much difference. The data of this paper comes from the input output table of China in 2007. The information industry data for communications equipment, computers and other electronic equipment manufacturing, postal services, information transmission, computer services and software industry, the comprehensive technical service industry data and. Narrow definition of tourism industry, including accommodation and catering industry as well as transportation and warehousing industry. Location entropy index calculation formula in the industrial output value is based on income approach to obtain the output data, it is calculated as: industrial added value $=$ compensation of employees net taxes on production + depreciation of fixed assets + operating surplus. For comparability and data integrity, this paper selects the data of 30 provinces and cities in China as the research object, which does not include Tibet, Hong Kong, Macao and Taiwan regions.

Agglomeration Degree and Integration Degree of IT Industry and Tourism Industry. The information industry and the tourism industry agglomeration degree and the agglomeration degree data are calculated by the formula 1 and 2, as the table 1 shows. From the data we can know thatthe agglomeration gapof information industry in China's 30 provinces and cities is quiet large.The highest concentration of the city of Beijing reached 3, while the lowest concentration in the province of Inner Mongolia is only 0.34. Information industry agglomeration degree in more than 1 provinces and cities have 6, mainly concentrated in Beijing, Shanghai, Tianjin, Guangdong, Jiangsu, Fujian and other economically more developed provinces. China's tourism industry agglomeration degree in more than 1 of the city reached 11, the highest concentration of provinces in Inner Mongolia, reaching 1.23. The lowest in the province of Jiangsu and Zhejiang, both 0.68 , with the highest concentration of the gap is only 0.55 . Thus, the tourism industry in our country more provinces and cities has reached a certain level of agglomeration, and the gap between the regions is small. From the degree of industrial concentration and the degree of integration of the relationship of view, if the agglomeration degree is more than 1 , the integration degree of the two industries is more than $1 \%$. It means that the agglomeration degree of it industry has a guiding role in the integration degree of it industry and tourism industry.

Table 1 LQ of Tourism and IT Industry and T of the Two Industries of Thirty Provinces and Cities

\begin{tabular}{|l|r|r|r|l|r|r|r|}
\hline Provinces & \multicolumn{1}{|l|}{$\begin{array}{l}\text { LQ of IT } \\
\text { Industry }\end{array}$} & $\begin{array}{l}\text { LQ of } \\
\text { Industry }\end{array}$ & T $(\%)$ & Provinces & $\begin{array}{l}\text { LQ of IT } \\
\text { Industry }\end{array}$ & $\begin{array}{l}\text { LQ of } \\
\text { Tourism } \\
\text { Industry }\end{array}$ & T $(\%)$ \\
\hline Anhui & 0.61 & 1.02 & 1.25 & Jiangxi & 0.74 & 0.94 & 1.03 \\
\hline Beijing & 3 & 1.11 & 1.76 & Liaoning & 0.68 & 0.93 & 0.68 \\
\hline Fujian & 1.14 & 1.04 & 2.03 & Neimenggu & 0.34 & 1.23 & 1.39 \\
\hline Gansu & 0.62 & 1.13 & 0.91 & Ningxia & 0.64 & 0.99 & 1.97 \\
\hline Guangdong & 1.9 & 0.77 & 1.22 & Qinghai & 0.68 & 0.81 & 1.32 \\
\hline Guangxi & 0.66 & 0.97 & 0.55 & Shandong & 0.54 & 0.79 & 0.96 \\
\hline Guizhou & 0.67 & 1.02 & 0.57 & Shanxi & 0.4 & 1.22 & 0.8 \\
\hline Hainan & 0.55 & 1.2 & 0.74 & Shaanxi & 0.74 & 0.92 & 0.63 \\
\hline Hebei & 0.45 & 1.16 & 1.69 & Shanghai & 1.78 & 0.86 & 1.66 \\
\hline Henan & 0.36 & 1.1 & 0.82 & Sichuan & 0.77 & 0.95 & 1.4 \\
\hline Heilongjiang & 0.41 & 0.84 & 1.2 & Tianjing & 1.87 & 0.93 & 1.23 \\
\hline Hubei & 0.78 & 0.92 & 0.89 & Xinjiang & 0.55 & 0.82 & 0.73 \\
\hline Hunan & 0.75 & 0.87 & 2 & Yunnan & 0.55 & 0.75 & 1.39 \\
\hline Jililn & 0.56 & 0.9 & 0.48 & Zhejiang & 0.87 & 0.68 & 1.04 \\
\hline
\end{tabular}




\begin{tabular}{|l|l|l|l|l|l|l|l|} 
Jiangsu & 1.55 & 0.68 & 1.02 & Chongqing & 0.71 & 1.06 & 1.62 \\
\hline
\end{tabular}

Analysis on Agglomeration Degree ofIT Industry and Integration Degree of IT Industry and Tourism Industry. The phenomenon of integration is more likely to happen in the industrial agglomeration areas. Therefore, this paper uses one-side-significance to test the correlation between the degree of industrial agglomeration and the degree of integration of the two industries. The results show that: there is no significant correlation between the degree of tourism industry agglomeration and the two industries, and the degree of information industry agglomeration is significantly related to the degree of integration of the two industries. The correlation coefficient is 0.329. It can be seen that the tourism industry doesn't have significant influences on the integration of the two industries; however, the IT industry shows a strong role in promoting the integration of the two industries.

\section{Research Conclusions and Implications}

We should expand the integrationapplication scope and deepen the depth of integration in order to obtain more extensive tourism industry chain innovation and development module. From the regional point of view, the areas which have the higher degree of information industry agglomerationalso have higher degrees of integration with the tourism industry.Therefore, China's tourism industry integration policy should give priority to the areas which have higher degree of information industry agglomeration to promote the agglomeration of the tourism industry and IT industry. Meanwhile, we should also actively cultivate new information industry agglomeration areas to promote the integration of the two industries in wider regions.

\section{Acknowledgements}

Program of Soft Science of Department of Science and Technology of Shaanxi Province in 2015

(Grant No. 2015KRM166)

\section{References}

[1]L Rayman-Bacchus,Amollia.Internet-based tourism services:business issues and trends[J].Futures,2001, 33(7):589

[2]Cindy Millman.E-commerce adoption by micro firms:a qualitative investigation in the UK tourism sector[J].International Journal of Online Marketing,2011, 1(2):1

[3]Amir Albadvi,Ghazaleh Saddad.Web site evaluation of Iranian tourism and hospitality organizations:an e-commerce web site features model[J].Journal of Hospitality Marketing \& Management,2012,21(2):155 